The INL is a

U.S. Department of Energy

National Laboratory

operated by

Battelle Energy Alliance

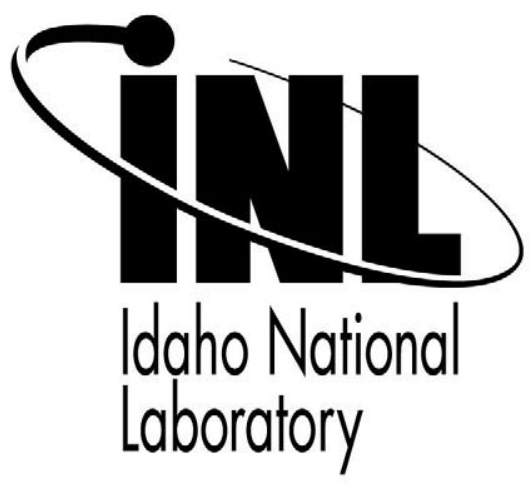

\title{
Hydrogen Production Performance Of A 10-Cell Planar Solid-Oxide Electrolysis Stack
}

\section{Third International Conference On Fuel Cell Science, Engineering and Technology}

\author{
J. E. O'Brien \\ C. M. Stoots \\ J. S. Herring \\ J. Hartvigsen
}

May 2005

This is a preprint of a paper intended for publication in a journal or proceedings. Since changes may not be made before publication, this preprint should not be cited or reproduced without permission of the author. This document was prepared as an account of work sponsored by an agency of the United States Government. Neither the United States Government nor any agency thereof, or any of their employees, makes any warranty, expressed or implied, or assumes any legal liability or responsibility for any third party's use, or the results of such use, of any information, apparatus, product or process disclosed in this report, or represents that its use by such third party would not infringe privately owned rights. The views expressed in this paper are not necessarily those of the United States Government or the sponsoring agency. 


\section{FUELCELL2005 - 74168}

\section{HYDROGEN PRODUCTION PERFORMANCE OF A 10-CELL PLANAR SOLID- OXIDE ELECTROLYSIS STACK}

\author{
J. E. O'Brien, C. M. Stoots, J. S. Herring \\ Idaho National Laboratory \\ Idaho Falls, ID 83415, USA; E-Mail: jzo@inel.gov
}

\author{
J. Hartvigsen \\ Ceramatec, Inc. \\ 2425 S 900 W, Salt Lake City, UT 84037 USA
}

\begin{abstract}
An experimental study is under way to assess the performance of solid-oxide cells operating in the steam electrolysis mode for hydrogen production over a temperature range of 800 to $900^{\circ} \mathrm{C}$. Results presented in this paper were obtained from a ten-cell planar electrolysis stack, with an active area of $64 \mathrm{~cm}^{2}$ per cell. The electrolysis cells are electrolytesupported, with scandia-stabilized zirconia electrolytes $(\sim 140$ $\mu \mathrm{m}$ thick), nickel-cermet steam/hydrogen electrodes, and manganite air-side electrodes. The metallic interconnect plates are fabricated from ferritic stainless steel. The experiments were performed over a range of steam inlet mole fractions $(0.1$ - 0.6), gas flow rates $(1000-4000 \mathrm{sccm})$, and current densities $\left(0\right.$ to $\left.0.38 \mathrm{~A} / \mathrm{cm}^{2}\right)$. Steam consumption rates associated with electrolysis were measured directly using inlet and outlet dewpoint instrumentation. Cell operating potentials and cell current were varied using a programmable power supply. Hydrogen production rates up to 100 Normal liters per hour were demonstrated. Values of area-specific resistance and stack internal temperatures are presented as a function of current density. Stack performance is shown to be dependent on inlet steam flow rate.
\end{abstract}

\section{INTRODUCTION}

Currently there is strong interest in the large-scale production of a secondary energy carrier for the non-electrical market. Hydrogen is of particular interest as the secondary energy carrier because it has the potential to be storable, transportable, and environmentally benign. Hydrogen can be used as a fuel for heating, electrical production (using fuel cells), and vehicles. It is also used as a raw material for many chemical processes, such as ammonia and methanol synthesis, iron ore processing, petroleum processing, and others. Currently hydrogen is produced primarily via steam reforming of methane. From a long-term perspective, methane reforming is not a viable process for large-scale production of hydrogen as a major energy carrier since such fossil fuel conversion processes consume non-renewable resources and emit greenhouse gases to the environment. Consequently, there is a high level of interest in production of hydrogen from water splitting via either thermochemical or electrolytic processes [1].

High-temperature nuclear reactors have the potential for substantially increasing the efficiency of hydrogen production from water, with no consumption of fossil fuels, no production of greenhouse gases, and no other forms of air pollution. Water-splitting for hydrogen production can be accomplished via high-temperature electrolysis or thermochemical processes, using high-temperature nuclear process heat. In order to achieve competitive efficiencies, both processes require hightemperature operation $\left(\sim 850^{\circ} \mathrm{C}\right)$. Thus these hydrogenproduction technologies are tied to the development of advanced high-temperature nuclear reactors. High-temperature electrolytic water-splitting supported by nuclear process heat and electricity has the potential to produce hydrogen with an overall system efficiency near those of the thermochemical processes [2, 3], but without the corrosive conditions of thermochemical processes and without the fossil fuel consumption and greenhouse gas emissions associated with hydrocarbon processes. Specifically, a high-temperature advanced nuclear reactor coupled with a high-efficiency hightemperature electrolyzer could achieve a competitive thermalto-hydrogen conversion efficiency of 45 to $55 \%$.

A research program is under way at the Idaho National Laboratory (INL) to simultaneously address the research and scale-up issues associated with the implementation of solidoxide electrolysis cell technology for hydrogen production from steam. We are conducting a logical progression of electrolysis stack testing activities, at increasing scales, along with a continuation of supporting research activities in the areas of materials development, single-cell testing, detailed computational fluid dynamics (CFD) analysis and systems modeling. Results of single (button) cell test activities 


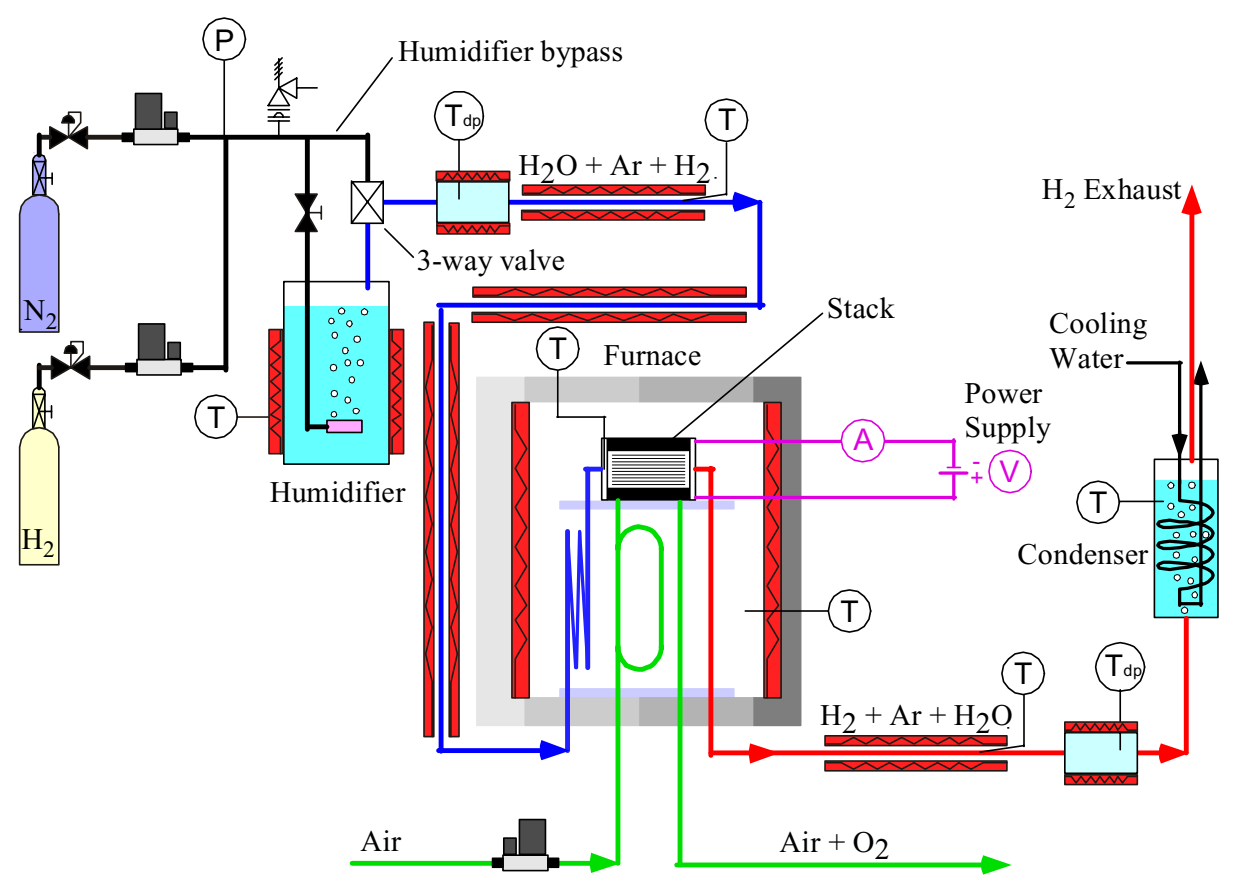

Figure 1: Schematic of experimental apparatus for electrolysis stack testing.

completed at the INL to date have been documented in several recent papers [4-7]. Button cell tests are useful for basic performance characterization of electrode and electrolyte materials and of different cell designs (e.g., electrodesupported). The single-cell results demonstrated efficient small-scale hydrogen production, with performance close to theoretical predictions. Cell performance was shown to be continuous from the fuel-cell to the electrolysis mode. The effects of steam starvation and thermal cycling on cell performance parameters were discussed. Based on these preliminary results, high-temperature electrolysis appears to be a viable means for hydrogen production using nuclear energy.

\section{NOMENCLATURE}

$A_{\text {cell }} \quad$ cell active area, $\mathrm{cm}^{2}$

ASR area-specific resistance, $\mathrm{Ohm} \mathrm{cm}^{2}$

$E \quad$ cell or stack operating potential, $\mathrm{V}$

$E_{o} \quad$ standard open-cell potential, $\mathrm{V}$

$E_{O C V} \quad$ Nernst or open-cell potential, V

$F \quad$ Faraday number, $\mathrm{J} / \mathrm{V} / \mathrm{mol}$

$\Delta \bar{g}_{f}^{o} \quad$ Gibbs energy of formation, $\mathrm{J} / \mathrm{mol}$

$\Delta \bar{h}_{f} \quad$ enthalpy of formation, $\mathrm{J} / \mathrm{mol}$

$\Delta H_{R} \quad$ enthalpy of reaction, $\mathrm{J} / \mathrm{mol}$

I electric current, amps

i current density, amps $/ \mathrm{cm}^{2}$

$j$ moles of electrons transferred per mole of steam electolyzed

$N_{\text {cells }} \quad$ number of cells in stack

$\dot{N} \quad$ molar flow rate, $\mathrm{mol} / \mathrm{s}$

$N_{\text {cells }} \quad$ number of cells in stack

$\begin{array}{ll}P & \text { pressure, } \mathrm{kPa} \\ P_{s t d} & \text { standard-state pressure, } \mathrm{kPa} \\ Q_{s} & \text { volumetric flow rate, } \mathrm{std} \mathrm{cm}^{3} / \mathrm{min} \\ R_{u} & \text { universal gas constant, } \mathrm{J} / \mathrm{mol} / \mathrm{K} \\ T & \text { temperature, } \mathrm{K} \\ V & \text { volts, } \mathrm{V} \\ V_{t n} & \text { thermal-neutral voltage, } \mathrm{V} \\ y & \text { mole fraction } \\ \eta_{t} & \text { electrolysis thermal efficiency }\end{array}$

\section{EXPERIMENTAL APPARATUS}

A schematic of the stack-testing apparatus is presented in Fig. 1. A photograph of the experimental hardware is provided in Fig. 2. Primary components include gas supply cylinders, gas mass-flow controllers, a humidifier, dewpoint measurement stations, temperature and pressure measurement, high temperature furnace, and a solid oxide electrolysis stack. Nitrogen was used as an inert carrier gas. The use of a carrier gas allows us to independently vary both the partial pressures and the flow rates of the steam and hydrogen gases while continuing to operate at atmospheric pressure. The flow rates of nitrogen, hydrogen and air are established by means of precision mass-flow controllers (Hastings Model HFC-302, with Hastings Model 400 electronics). Air flow to the stack is supplied by the laboratory shop air system, after passing through a two-stage extractor / dryer unit.

Downstream of the mass-flow controller, nitrogen is mixed with a smaller flow of hydrogen gas. Hydrogen is included in the inlet flow as a reducing gas in order to help prevent oxidation of the Nickel cermet electrode material. The nitrogen/ hydrogen gas mixture is mixed with steam by means of a heated humidifier. The humidifier (visible in Fig. 1) consists of 


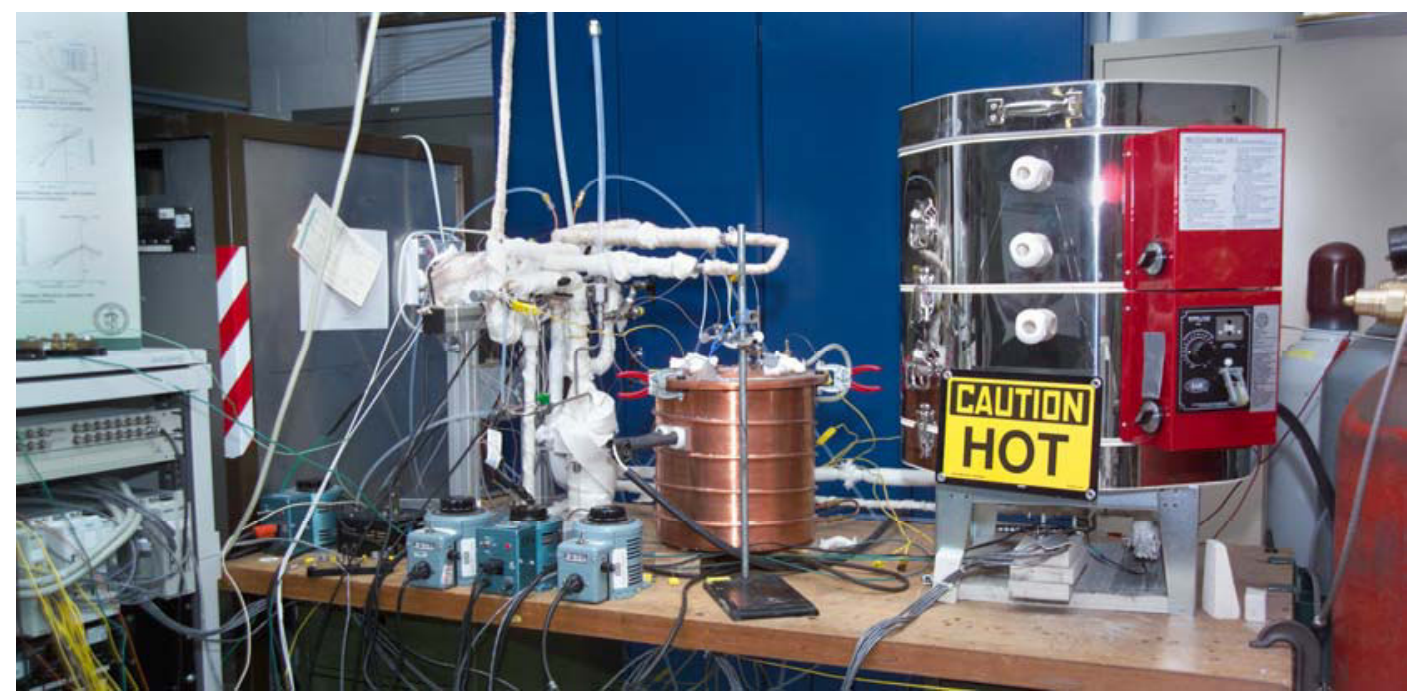

Figure 2. High-temperature electrolysis hardware.

a heated stainless-steel vessel containing demineralized/ deionized water through which the nitrogen / hydrogen flow is bubbled. An aquarium-style bubbler was used for this purpose. The dewpoint temperature of the nitrogen / hydrogen / steam gas mixture exiting the humidifier is monitored continuously using a precision dewpoint sensor (Vaisala Model HMP247). These measurements have indicated that the dewpoint temperature of the gas mixture leaving the humidifier is very close to the water bath temperature, but not necessarily equal to it. The humidifier is fitted with a clamp heater and is externally insulated. The temperatures of both the humidifier wall and the water bath are monitored continuously using thermocouples. The humidifier temperature is maintained at a constant setpoint value using feedback control. Since the vapor pressure of the water and the resulting partial pressure of the steam exiting the humidifier are determined by the water bath temperature, the water vapor mass flow rate is directly proportional to the carrier gas flow rate for a specified bath temperature. Also, since the nitrogen and hydrogen flow rates are fixed by the mass flow controllers, and the steam partial pressure is fixed by the bath temperature, the complete gas composition is precisely known at all times. All gas lines located downstream of the humidifier are heat-traced in order to prevent steam condensation. Gas line temperatures are monitored by thermocouples and controlled by means of variable transformers.

During system cool-down, it is desirable to maintain nitrogen and hydrogen gas flows. In order to allow for the flow of a dry nitrogen / hydrogen mixture through the system during cool-down, without any possibility of steam condensation, a humidifier bypass was incorporated into the gas flow lines. Humidifier bypass is achieved by closing the shut-off valve in the bubbler line and changing the position of the 3-way valve located at the inlet to the first dewpoint measurement station (see Fig. 1). The humidifier also incorporates a pressure relief valve to avoid any possibility of over-pressurization.
The inlet dewpoint measurement station is located immediately downstream of the humidifier. This measurement station consists of a stainless-steel vessel that houses the dewpoint sensor head, and a temperature probe. The sensors and the inlet and outlet gas lines are connected to the vessel using compression fittings. The outside of the vessel is fitted with a clamp heater and maintained at a temperature above the gas mixture dewpoint value at all times using feedback control. The outlet dewpoint measurement station is identical to the inlet station.

A close-up photograph of the tested 10-cell solid-oxide electrolysis stack is shown in Fig. 3. The stack was fabricated by Ceramatec, Inc. of Salt Lake City, UT. This stack has a percell active area of $64 \mathrm{~cm}^{2}$. It is designed to operate in cross flow, with the steam / hydrogen gas mixture entering the inlet manifold on the right in the photograph, and exiting through the outlet manifold, visible on the left in the photograph. Air flow enters at the rear though an air inlet manifold (not visible in Fig. 3) and exits at the front directly into the furnace. The power lead attachment tabs, integral with the upper and lower interconnect plates are also visible in the photograph. Stack operating voltages were measured using wires that were directly spot-welded onto these tabs.

Since the stack air outlet plane is not enclosed, the small air flow channels are accessible for instrumentation. Four intermediate cell voltages were monitored using small-diameter wires inserted into these air flow channels. In addition, four miniature thermocouples were inserted into the air flow channels to monitor internal stack temperatures. These thermocouples were inconel-sheathed, 0.010-inch $(250 \mu \mathrm{m})$ $\mathrm{OD}$, mineral-insulated, ungrounded, type-K thermocouples.

The internal components of the stack are shown in Fig. 4. The interconnect plate, shown on the left in Fig. 4, is fabricated primarily from ferritic stainless steel. It includes an impermeable separator plate ( $\sim 0.46 \mathrm{~mm}$ thick) with edge rails and two corrugated "flow fields," one on the air side and one on the steam/hydrogen side. The height of the flow channel 


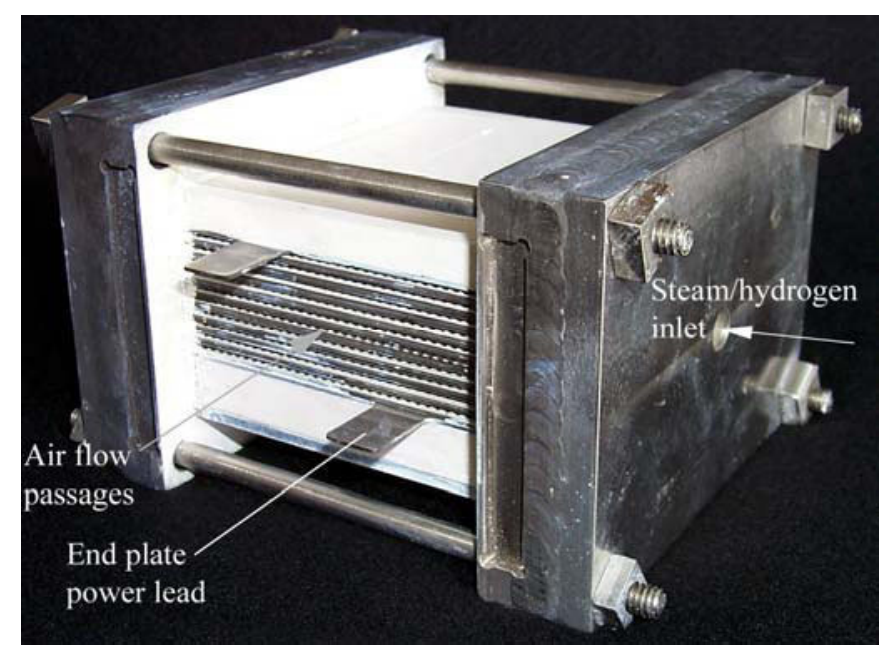

Figure 3. Detail of stack.

formed by the edge rails and flow fields is $1.0 \mathrm{~mm}$. Each flow field includes 32 perforated flow channels across its width to provide uniform gas-flow distribution. The steam/ hydrogen flow field (visible in Fig. 4) is fabricated from nickel foil. The air-side flow field is ferritic stainless steel. The interconnect plates and flow fields also serve as electrical conductors and current distributors. To improve performance, the air-side separator plates and flow fields are pre-surface-treated to form a rare-earth conductive oxide scale. A perovskite rare-earth coating is also applied to the separator-plate oxide scale by either screen printing or plasma spraying. On the steam/hydrogen side of the separator plate, a thin $(\sim 10 \mu \mathrm{m})$ nickel metal coating is applied.

The electrolyte/electrode assembly is shown on the right of Fig. 4. The electrolyte is scandia-stabilized zirconia, about 140 $\mu \mathrm{m}$ thick. The air-side electrode (anode in the electrolysis mode), visible in the figure, is a strontium-doped manganite. The electrode is graded, with an inner layer of manganite/ zirconia $(\sim 13 \mu \mathrm{m})$ immediately adjacent to the electrolyte, a middle layer of pure manganite $(\sim 18 \mu \mathrm{m})$, and an outer bond layer of cobaltite. The steam/ hydrogen electrode (cathode in the electrolysis mode) is also graded, with a nickel-zirconia cermet layer $(\sim 13 \mu \mathrm{m})$ immediately adjacent to the electrolyte and a pure nickel outer layer $(\sim 10 \mu \mathrm{m})$.

A photograph of the stack, mounted on its inconel test fixture, and resting on the furnace base, is shown in Fig. 5. The power leads are inconel rods insulated with alumina tubing. The hydrogen/steam and air inlet tubes are coiled to provide additional length for heat transfer upstream of the stack. The furnace used for stack testing is an electrically heated pottery kiln (Skutt Model KS818-3), capable of maintaining temperatures up to $1250^{\circ} \mathrm{C}$. For the electrolysis application, it was configured to allow feedback temperature control, via the system controller computer. Electrolysis testing was performed in the temperature range of $800-900^{\circ} \mathrm{C}$.

Measurement of the outlet dewpoint temperature, downstream of the electrolysis stack, allows for direct determination of the change in dewpoint, the rate of steam reduction and the corresponding rate of hydrogen production

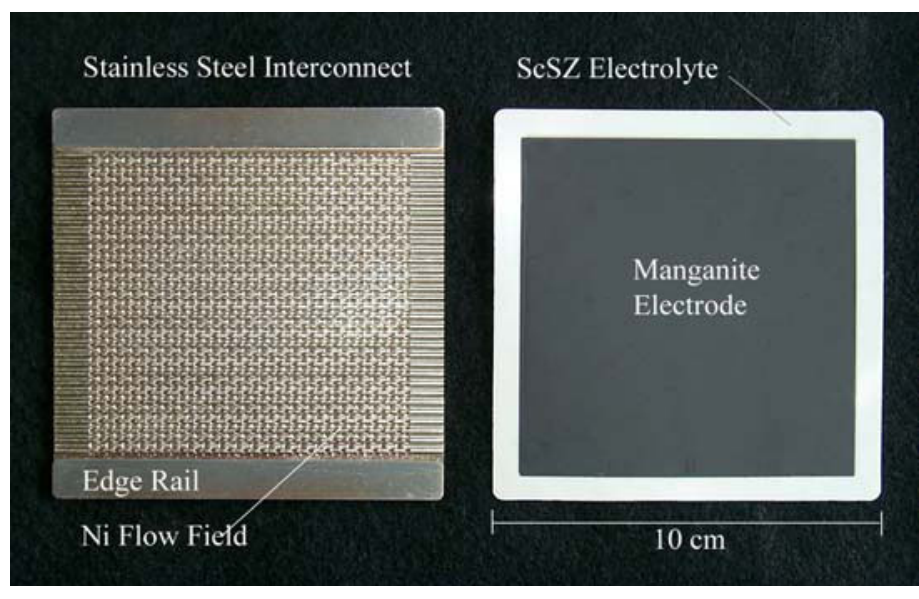

Figure 4. Interconnect plate and single electrolysis cell.

during electrolysis testing. All testing was performed at essentially ambient laboratory pressure, about $85 \mathrm{kPa}$ for our $4700 \mathrm{ft}$. elevation.

Stack voltage and current values were controlled by means of a programmable DC power supply (Lambda Zup 20-40), rated for $20 \mathrm{~V}$ and 40 amps. The power supply could be operated in either the constant-current or constant voltage modes. This power supply was interfaced to the system controller computer via an RS232 interface. Cell amperage and the voltage across the stack are monitored continuously. Stack current measurements are obtained from the power supply, with

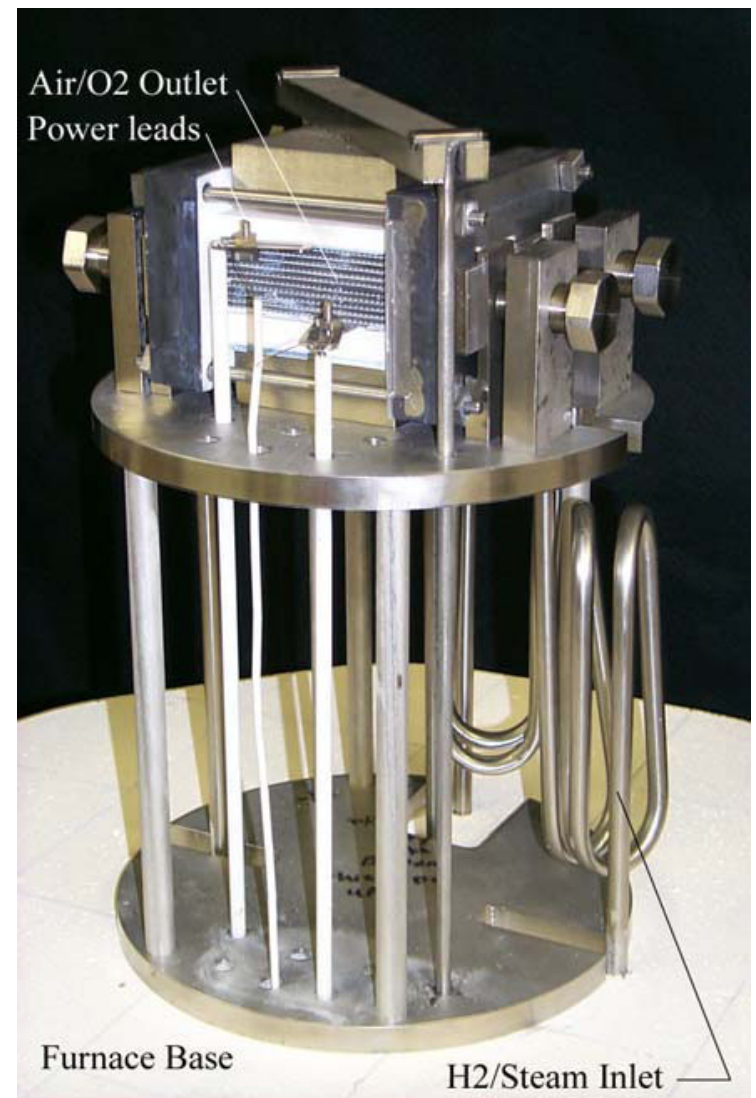

Figure 5. Ten-cell stack mounted on fixture for testing at INL. 
redundant measurements provided by a precision shunt $(50 \mathrm{~A}=$ $200 \mathrm{mV}$ ). Temperature and humidity signals from the humidity measurement stations were wired directly into two dewpoint transmitter electronics units (Vaisala Model HMP247). These units were also interfaced to the system controller computer via an RS232 interface.

Signals from all thermocouple channels, mass-flow controllers, pressure transducer, and stack voltage taps were wired into a modular data acquisition system (National Instruments Model SCXI) which was configured for this application with a 32-channel analog input module and an eight-channel analog output module. The analog output module was used to provide control signals $(4-20 \mathrm{~mA})$ for feedback temperature control of the humidifier, the humidity measurement stations, and the furnace. Data acquisition and instrument control were implemented for these tests using a Labview (National Instruments, version 6.1) program (virtual instrument) specifically created for this experiment. Temperature control of the humidifier, the humidity sensing volumes, and the furnace was accomplished using customized PID control algorithms.

\section{EXPERIMENTAL PROCEDURE}

Prior to each test, a slow automated heat-up of the electrolysis stack is performed with the stack in the open-cell condition until the desired test temperature is achieved. A heating time of 12 hours is typically used to take the stack from room temperature to $800^{\circ} \mathrm{C}$. During this time, the humidifier, humidity sensing station, and heat tracing temperatures are also established. Nitrogen, hydrogen, and air gas flow rates are established for the heatup by adjusting the set points on the mass-flow controller electronics unit. The humidifier is temperature desired for the heatup process is also established at this time. When the furnace temperature reaches about $500^{\circ} \mathrm{C}$, at which point the electrolyte material begins to conduct oxygen ions, data recording was initiated in order to document details of the heat-up process, including open-cell potential. Theoretical open-cell potentials can be predicted from the Nernst equation for any given gas composition as a function of temperature. Comparison of measured and predicted open-cell potential values during heat-up provides a useful system diagnostic. A significant departure of measured open-cell potential from the predicted value can indicate a problem such as a cracked cell or leakage. Some small leakage is expected for the stack configuration, however.

Two types of stack characterization tests were performed: DC potential sweeps and steady-state tests. DC potential sweeps were performed by programming the power supply to vary the applied stack voltage over a range, typically from $8 \mathrm{~V}$ to $18 \mathrm{~V}$. Applied voltage values lower (in magnitude) than the open-cell potential $(\sim 1 \mathrm{~V} /$ cell $)$ yield the fuel-cell mode of operation while applied voltages higher than the open-cell value yield electrolysis. The sweep rate for these tests was set at about $8 \mathrm{mV} / \mathrm{s}$, so each sweep required a total time of about 25 minutes. Results of the DC potential sweeps allow for determination of the stack area-specific resistance and hydrogen production rates. Steady-state tests were performed by selecting an appropriate stack operating voltage and observing the hydrogen-production performance over a relatively long period of time, to determine whether any degradation in performance occurs over the long term.

\section{DATA REDUCTION}

Open-cell potentials can be predicted for any gas composition from the Nernst equation, which for the hydrogen / oxygen / steam system takes the form:

$$
E=E_{o}-\frac{R_{u} T}{j F} \ln \left[\left(\frac{y_{H 2 O}}{y_{H 2} y_{O 2}^{1 / 2}}\right)\left(\frac{P}{P_{s t d}}\right)^{-1 / 2}\right]
$$

where $\mathrm{E}_{\mathrm{o}}$ is the standard open-cell potential, given by

$$
E_{o}=\frac{-\Delta \bar{g}_{f}^{o}}{2 F} .
$$

Since we are using air as our source of oxygen, the value of $\mathrm{y}_{\mathrm{O} 2}$ at the stack inlet is fixed at 0.21. In the stack configuration, potentials are usually measured across the entire stack, so the overall stack open-cell potential given by:

$$
E_{\text {stack }}=N_{\text {cells }} E
$$

where $\mathrm{E}$ is the single-cell open-cell potential, from Eqn. (1).

Inlet and outlet gas stream dewpoint temperatures were directly measured in this work. Aside from the fact that the measured difference between outlet and inlet dewpoint temperature (dewpoint depression) is a useful indication of cell performance, measured dewpoints permit direct determination of inlet and outlet steam mole fractions and the corresponding hydrogen production rate. From the measured dewpoint temperatures, water vapor pressures may be calculated from an appropriate correlation (e.g., Antoine). The inlet and outlet mole fractions of steam can then be obtained from:

$$
y_{H 2 O, i}=\frac{P_{H 2 O, i}}{P} ; \quad y_{H 2 O, o}=\frac{P_{H 2 O, o}}{P} .
$$

It should be noted that since the mole fraction of steam in the inlet gas flow is determined strictly by the dewpoint temperature, the total inlet flow rate of steam is therefore directly proportional to the sum of the molar flow rates of nitrogen plus hydrogen:

$$
\dot{N}_{H 2 O, i}=\frac{\left(\dot{N}_{N 2}+\dot{N}_{H 2, i}\right) y_{H 2 O, i}}{1-y_{H 2 O, i}} .
$$

The magnitude of the total inlet steam flow rate is important in determining whether or not steam starvation is likely to occur during electrolysis operation.

The inlet mole fraction of hydrogen, $\mathrm{y}_{\mathrm{H} 2, \mathrm{i}}$ is determined by the steam mole fraction and the ratio of the nitrogen flow rate to the hydrogen flow rate, both of which are determined by the setpoint values established on the mass flow controllers: 


$$
\begin{gathered}
y_{H 2, i}=\frac{1-y_{H 2 O, i}}{1+\dot{N}_{N 2} / \dot{N}_{H 2, i}} \\
\dot{N}_{N 2}=Q_{s, N 2} \frac{P_{s t d}}{R_{u} T_{s t d}} \\
\dot{N}_{H 2, i}=Q_{s, H 2} \frac{P_{s t d}}{R_{u} T_{s t d}} .
\end{gathered}
$$

Finally, the molar rates of hydrogen production and steam consumption may be determined from:

$$
\begin{gathered}
\Delta \dot{\mathrm{N}}_{H 2}=-\Delta \dot{\mathrm{N}}_{H 2 O} \\
\Delta \dot{\mathrm{N}}_{H 2}=\dot{N}_{H 2 O, i}-\left(\dot{N}_{H 2 O, i}+\dot{N}_{H 2, i}+\dot{N}_{N 2}\right) y_{H 2 O, o}
\end{gathered}
$$

The molar rates of hydrogen production and steam consumption during electrolysis can also be predicted independently from the measured stack electrical current:

$$
\Delta \dot{N}_{H 2}=\frac{I}{2 F} N_{\text {cells }}=-\Delta \dot{N}_{H 2 O} .
$$

where $N_{\text {cells }}$ is the number of cells in the stack. The product of the electrical current and the number of cells is the total ionic current in the stack.

Since we have directly measured both inlet and outlet dewpoint temperatures, we have generated plots comparing hydrogen production rates based on stack current to hydrogen production rates based on the measured change in dewpoint over a range of stack current densities.

An important performance parameter that quantifies the ohmic losses associated with the operation of solid-oxide electrolysis cells is the area-specific resistance (ASR). This quantity is defined as:

$$
A S R=\frac{E-E_{\text {ref }}}{i} ; \quad i=\frac{I}{A_{\text {cell }}}
$$

where $\mathrm{E}$ is the applied potential, $\mathrm{E}_{\text {ref }}$ is the reference or opencell potential and $i$ is the current density $\left(\mathrm{A} / \mathrm{cm}^{2}\right)$.

A thermal efficiency, $\eta_{t}$, can be defined for solid-oxide electrolysis cells, analogous to the solid-oxide fuel cell efficiency definition. The thermal efficiency quantifies the heating value of the hydrogen produced by electrolysis per unit of electrical energy consumed. It can be defined in terms of cell operating potential as:

$$
\eta_{t}=\frac{-\Delta \bar{h}_{f} / 2 F}{E}
$$

The thermal efficiency for the fuel-cell mode of operation is the inverse of Eqn. (15). Since we have indirectly measured the rate of hydrogen production from our dewpoint measurements, we can also calculate the thermal efficiency independently using:

$$
\eta_{t}=\frac{\Delta \dot{N}_{H 2} \Delta \bar{h}_{f}}{E I}
$$

where $\Delta \dot{N}_{H 2}$ is obtained from the dewpoint measurements. It should be noted that the value of the thermal efficiency defined in this manner for electrolysis can exceed 1.0. For the ideal case, the cell potential would approach the reversible limit, $E_{o}=-\Delta \bar{g}_{f}^{o} / 2 F$, yielding:

$$
\eta_{t, \text { ideal }}=\frac{\Delta \bar{h}_{f}}{\Delta \bar{g}_{f}^{o}}
$$

which for steam electrolysis at $850^{\circ} \mathrm{C}$ is equal to 1.34 . For cases with variable gas compositions, the open-cell potential is given by the Nernst Eqn. (1), and the corresponding efficiency limit varies accordingly.

In the electrolysis mode of operation, the electrochemical reaction is endothermic, and ohmic heating is always present. At operating voltages between the open-cell potential and the thermal neutral voltage, the endothermic reaction heat requirement is greater in magnitude than the ohmic heating, and a net cooling effect prevails in the stack [4]. The thermal neutral voltage, given by:

$$
V_{t n}=\frac{\Delta H_{R}}{2 F}
$$

is $1.287 \mathrm{~V}$ at $800^{\circ} \mathrm{C}$, or $12.87 \mathrm{~V}$ for the 10 -cell stack. Beyond this operating voltage, ohmic heating exceeds the endothermic reaction heat requirement and a net heating effect prevails.

\section{RESULTS}

The initial stack heatup from room temperature to $800^{\circ} \mathrm{C}$ took place over a period of about 11 hours. During this time, all measured experimental conditions were recorded. A plot of stack overall open-cell potential during the last portion of the heatup, from 600 to $800^{\circ} \mathrm{C}$ is presented in Fig. 6 as a function of stack temperature. The Nernst potentials are based on Eqn. (1), with the hydrogen and steam mole fractions determined from the known hydrogen and nitrogen mass-flow rates and the measured dewpoint temperature. The measured stack open-cell potential begins to follow the correct trend at temperatures above $\sim 500^{\circ} \mathrm{C}$. Below this temperature, the zirconia electrolyte ionic conductivity is too low. The measured stack open-cell potentials shown in the figure are somewhat lower than the theoretical values. This is probably due to some small gas leakage through the stack edge seals. Hydrogen mass diffusion can be significant at these temperatures. In particular, preferential diffusion of hydrogen can occur through the porous ceramic-paste edge seals. Better agreement between theoretical and measured open-cell potentials was observed at the higher 


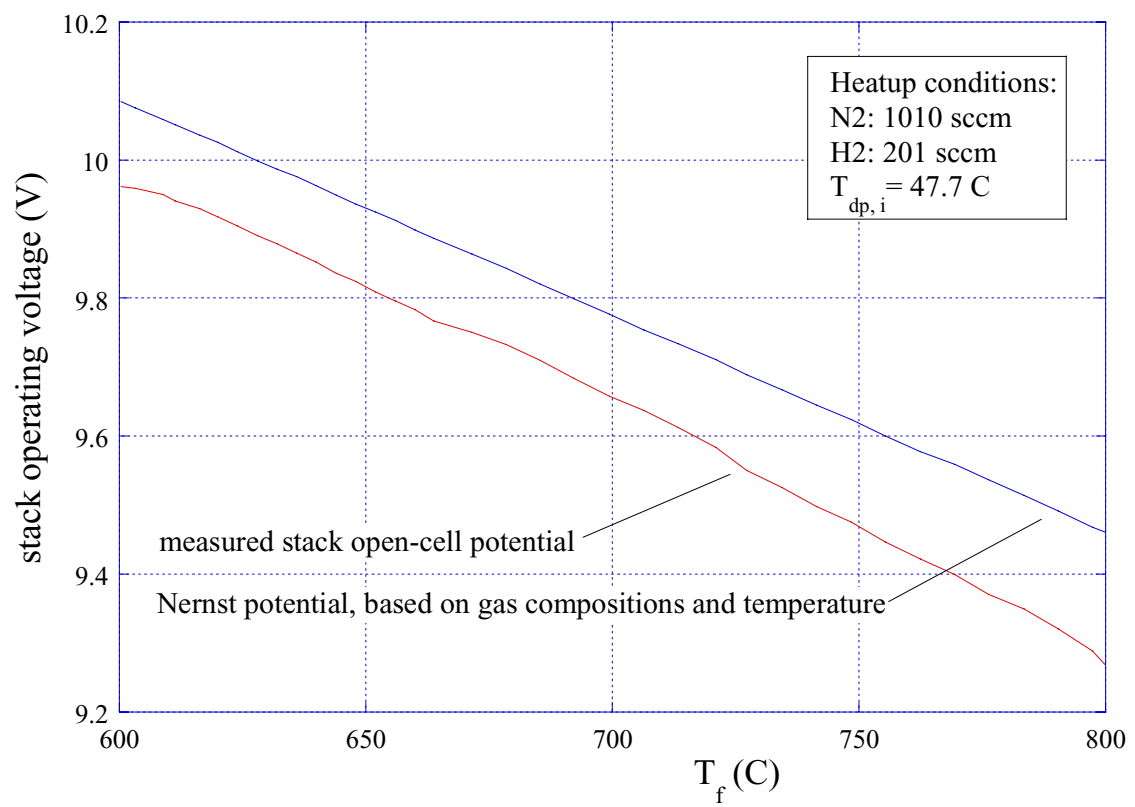

Figure 6. Stack open-cell potential during heatup.

gas flow rates and higher inlet dewpoint values used during subsequent stack performance characterization tests.

A series of DC potential sweeps was performed in order to characterize the performance of the stack over a range of operating conditions. Each sweep was performed in the electrolysis mode with the furnace temperature and gas flow rates set at fixed values, but with the power supply programmed to vary the applied voltage over a range, typically from 8 to 20 volts. The corresponding stack operating voltage range was about 8 to 14 volts, due to resistive losses in the power lead wires and at the stack power lead attachment tabs. The power supply sweep rate was set at $\sim 8 \mathrm{mV} / \mathrm{s}$, so the duration of each sweep was about 25 minutes. At the gas flow rates used in the stack, the response time of the downstream dewpoint sensor was fast enough to provide continuous outlet dewpoint measurements during the sweep. These sweeps were useful for obtaining information about cell area-specific resistance (ASR) values and steam starvation limits.

Results of several representative sweeps are shown in Fig. 7 in the form of operating voltage versus current density. Test conditions for each of the six sweeps are tabulated in the figure. Four of the sweeps were obtained at a furnace temperature of $800^{\circ} \mathrm{C}$ and one at $830^{\circ} \mathrm{C}$. Inlet dewpoint values were varied as shown. Theoretical open-cell potential values are also shown in the figure for each sweep using a single data point at zero current density. Note that the measured open-cell potentials are

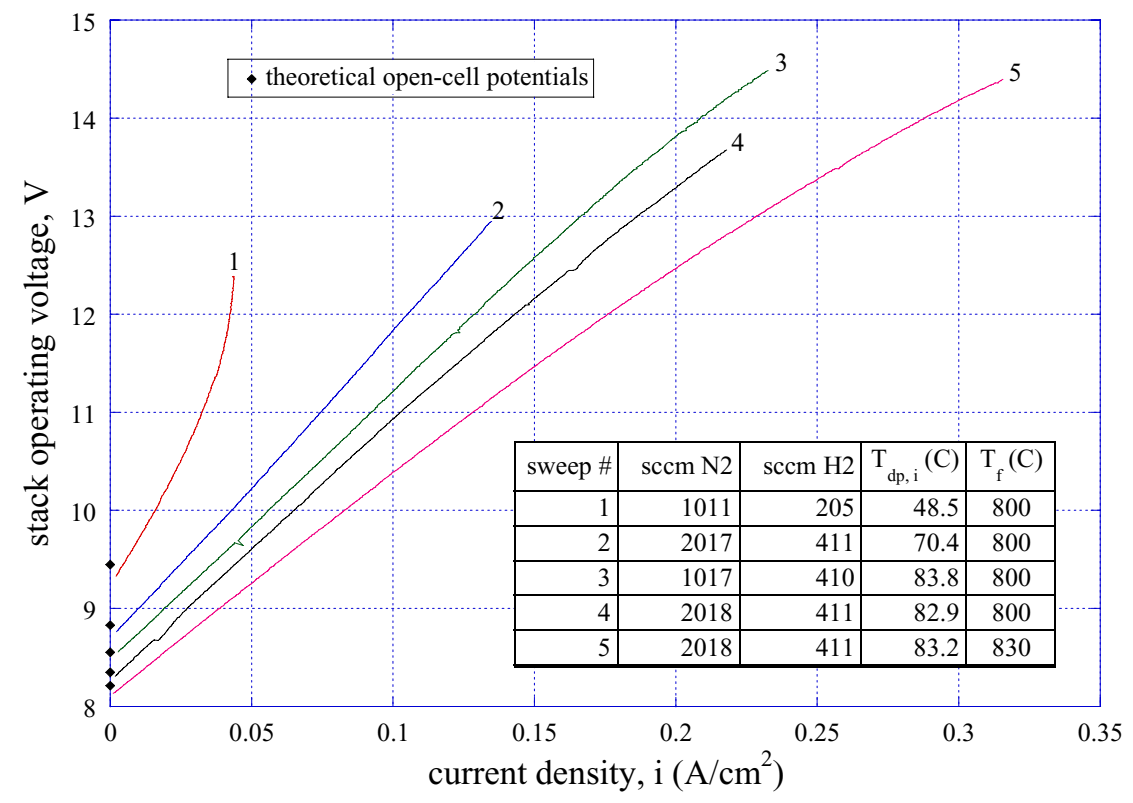

Figure 7. Stack operating potential as a function of current density. 


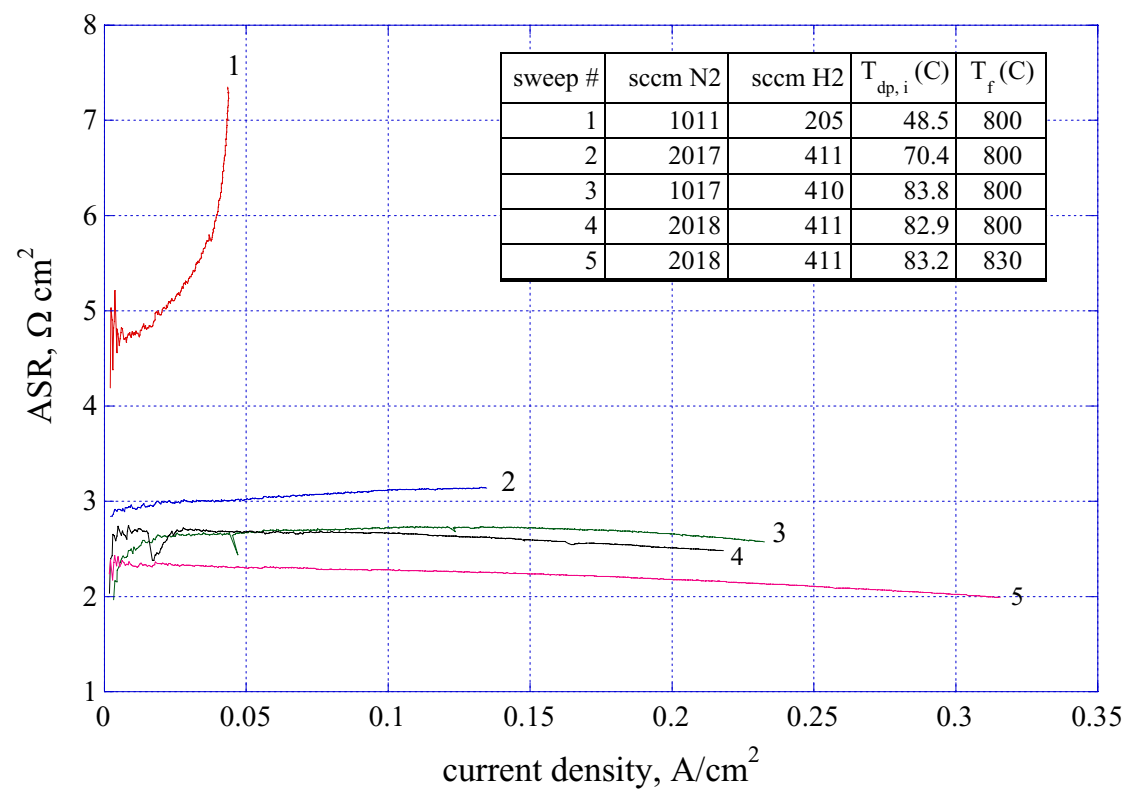

Figure 8. Per-cell area-specific resistance measured during DC potential sweeps.

in excellent agreement with these theoretical values for each sweep. Sweep \#1 was performed with a relatively low inlet steam flow rate, corresponding to the low inlet dewpoint value of $48.5^{\circ} \mathrm{C}$ and relatively low nitrogen and hydrogen flow rates. This sweep has a relatively high slope on V-i coordinates, indicating a relatively high ASR value. This sweep also clearly shows the effects of steam starvation; the slope of the V-i curve increases dramatically as the current density is increased. The outlet dewpoint temperature corresponding to the highest current density shown in this figure was only $4^{\circ} \mathrm{C}$. Sweep $\# 2$ was performed at an intermediate steam concentration, with an inlet dewpoint temperature of $70^{\circ} \mathrm{C}$. This sweep exhibits nearly linear behavior over the range of current densities shown, with a much smaller slope than sweep \#1. Sweeps 3 and 4 are nearly linear at low current densities, then slightly concavedown at higher current densities. Sweep \#5 has a shallower slope than the others, consistent with the higher operating temperature of $830^{\circ} \mathrm{C}$. This $\mathrm{V}-\mathrm{i}$ curve also shows more distinct concave-down characteristics at higher current densities.

Per-cell area-specific resistance values corresponding to the sweeps of Fig. 7 are presented in Fig. 8 as a function of current density. Highest ASR values were observed for the cases with low steam concentrations. Sweep \#1 had ASR values near 4.5 at low current density, increasing rapidly for higher current densities, due to steam starvation. Sweep \#2, at intermediate steam concentration had an intermediate ASR value near 3.0, increasing slightly with increasing current density. Sweeps 3 and 4 were similar, with ASR values near

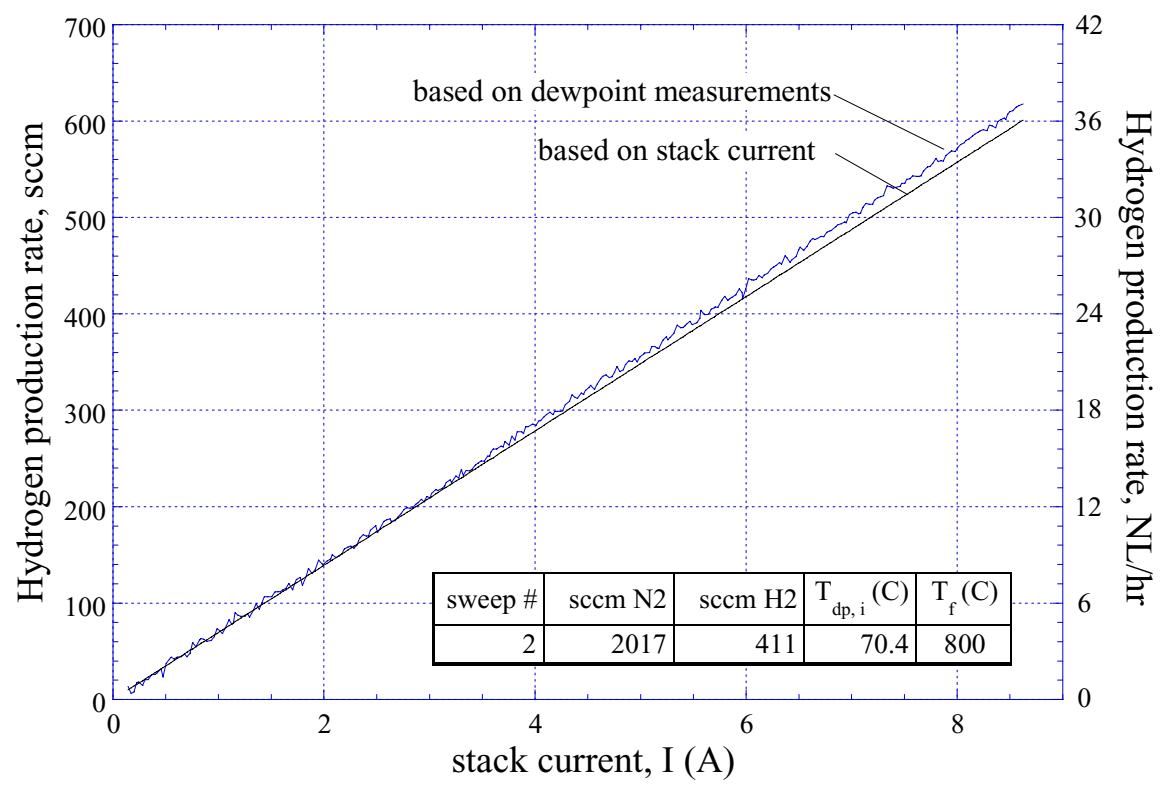

Figure 9. Hydrogen production rates during DC potential sweep. 


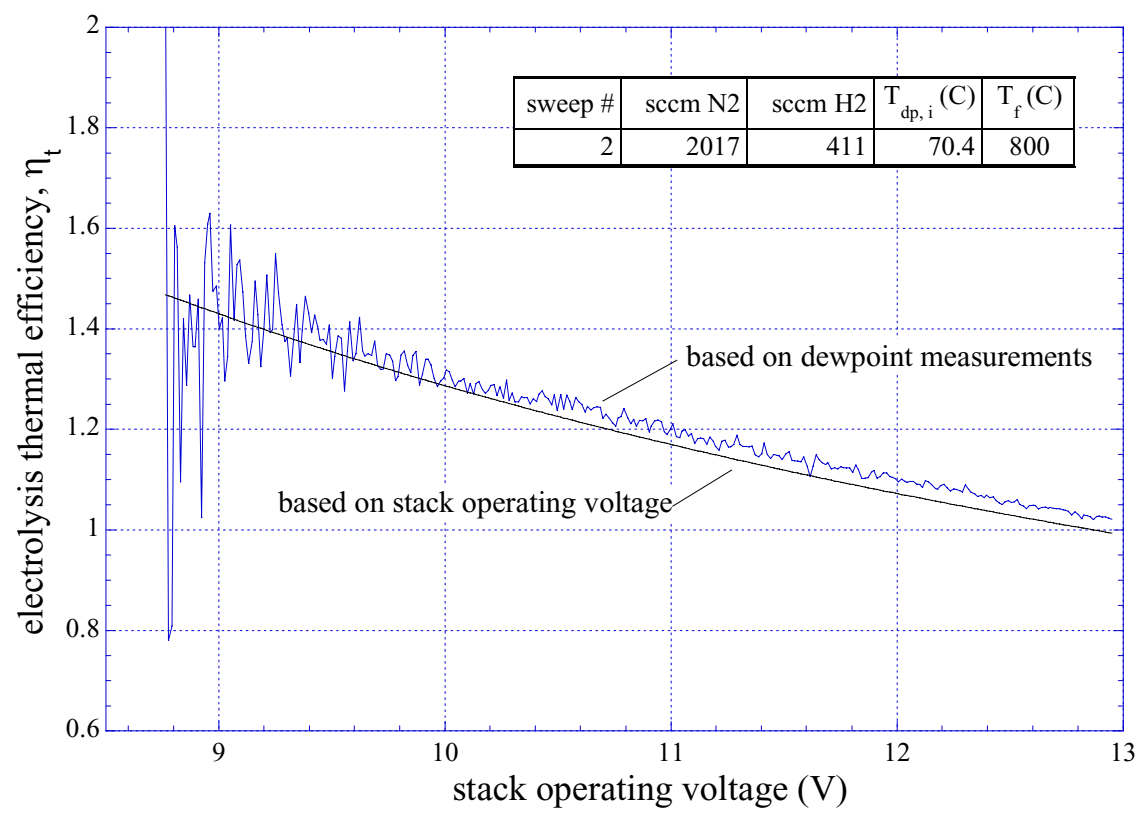

Fgiure 10. Electrolysis efficiencies as a function of operating voltage.

2.5 , decreasing slightly at high current density. Sweep \#5, at an operating temperature of $830^{\circ} \mathrm{C}$ showed the lowest ASR value, around 2.2 , decreasing significantly with increasing current density.

Hydrogen production rates can be calculated directly from the stack electric current (Eqn. 11) and independently from the measured inlet and outlet dewpoint measurements (Eqn. 10). A representative plot of hydrogen production during DC potential sweep \#2 is shown in Fig. 9. The left-hand vertical scale is in sccm and the right-hand vertical axis is in NL/hr. The currentbased hydrogen production rate is simply a straight line since hydrogen production is directly proportional to the current. The dewpoint-based measurement shows some scatter associated with the instantaneous measured inlet and outlet dewpoint values. Agreement between the two measurements is generally very good. Hydrogen production rates as high as 90 $\mathrm{NL} / \mathrm{hr}$ were achieved with this stack.

Electrolysis efficiencies corresponding to the hydrogen production rates shown in Fig 9 are presented in Fig. 10 as a function of stack operating voltage. Efficiency values based on stack operating voltage are calculated from Eqn. (13). Values based on the measured change in dewpoint temperature are calculated from Eqn. (14). These independent efficiency measurements shown in Fig. 10 are in excellent agreement. The dewpoint-based values exhibit large fluctuations near the open-cell potential primarily due to the fact that the measured electric current is near zero, so any small error is magnified. Electrolysis efficiency decreases monotonically with increasing stack operating voltage. The efficiency is a maximum at the open-cell potential and it is equal to 1.0 at the thermal neutral voltage $\left(1.287 \mathrm{~V}\right.$ at $\left.800^{\circ} \mathrm{C}\right)$. Electrolysis operation is a tradeoff between maximum efficiency and hydrogen production rare. Low stack ASR values allow for achievement of a specified hydrogen production rate (or current density) at a lower operating voltage and higher electrolysis efficiency.
Temperatures measured during a DC potential sweep are presented in Fig. 11 as a function of operating voltage. Stack internal temperature measurements were obtained using miniature thermocouples inserted into the air flow channels. Stack internal \#1 was located in the center position of the center air flow channel, stack internal \#2 was located along the edge of the center cell closest to the steam/hydrogen exit, stack internal \#3 was located along the edge of the center cell closest to the steam/hydrogen inlet, and stack internal \#4 was located at the center of the top air flow channel. The air inlet temperature is obtained from a thermocouple located inside the air inlet manifold. This thermocouple is used as the process variable for feedback control of the furnace power. The "furnace" temperature is obtained form a thermocouple located in the main part of the furnace outside of the test fixture.

The air inlet temperature remains virtually fixed during the DC potential sweep because this temperature is used for feedback control to establish the stack operating temperature. The four internal stack thermocouples respond as expected during the sweep. At voltages between the open-cell potential and the thermal neutral voltage, in the electrolysis mode, the stack internal temperatures are lower than the gas inlet and furnace setpoint temperatures because at this operating condition, the endothermic reaction heat requirement is greater than the ohmic heating [4] and there is a net cooling effect on the stack. A thermal minimum point is reached at an operating voltage near $11.2 \mathrm{~V}$. The magnitude of the stack cooling and heating effects is greatest at the center of the stack, as indicated by the response of internal stack temperature 1. Internal stack temperatures 2 and 3 respond similarly to the center thermocouple, but with smaller amplitude, due to convective and radiative heat transfer effects near the edges of the stack. Stack internal \#4 is in the top air flow channel, so its response is also constrained by radiant heat transfer. Note that the "furnace" thermocouple responds in a direction that is opposite 


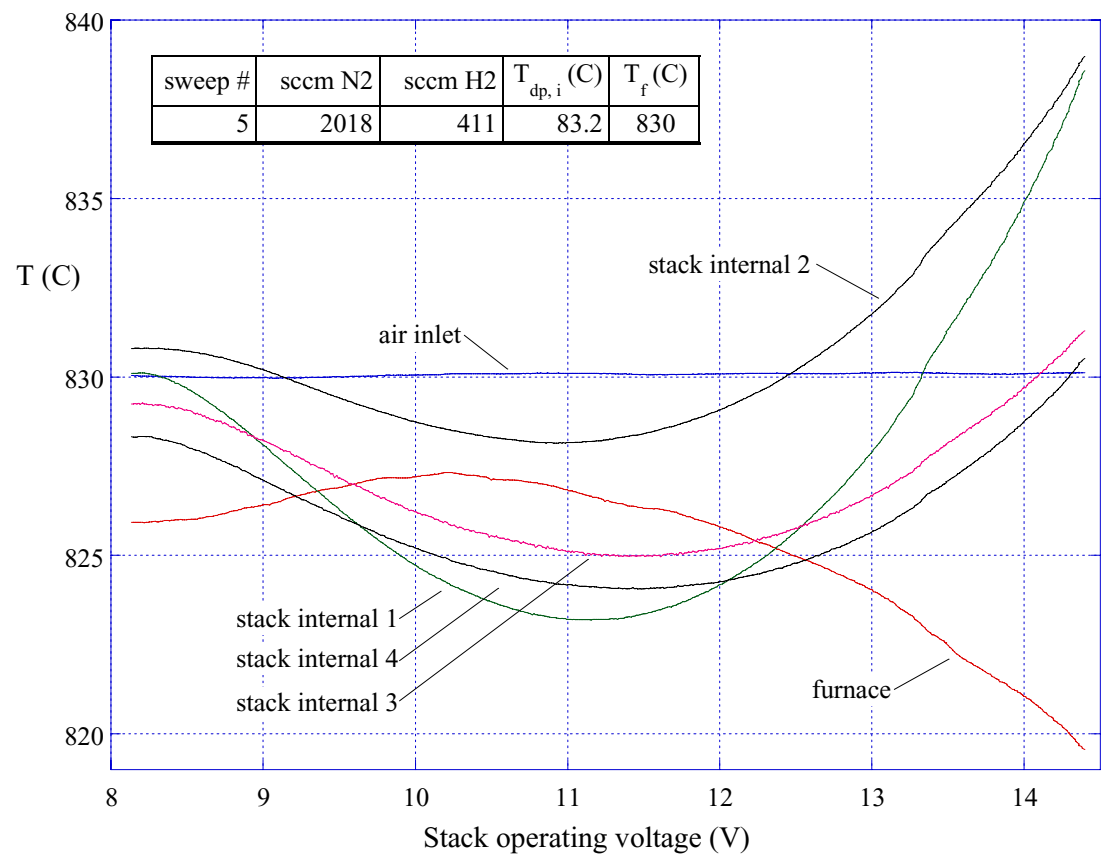

Figure 11. Stack temperatures measured during DC potential sweep.

of the stack internal thermocouples. This is because the feedback control demands more furnace power when the stack is tending to cool off and less power when the stack is tending to heat up.

\section{CONCLUSIONS}

An experimental study is under way to assess the performance of solid-oxide cells operating in the steam electrolysis mode for hydrogen production over a temperature range of 800 to $900^{\circ} \mathrm{C}$. Results presented in this paper were obtained from a ten-cell planar electrolysis stack, with an active area of $64 \mathrm{~cm}^{2}$ per cell. The electrolysis cells are electrolytesupported, with scandia-stabilized zirconia electrolytes $(\sim 140$ $\mu \mathrm{m}$ thick), nickel-cermet steam/hydrogen electrodes, and manganite air-side electrodes. The metallic interconnect plates are fabricated from ferritic stainless steel. The experiments were performed over a range of steam inlet mole fractions $(0.1$ $-0.6)$, gas flow rates $(1000-4000 \mathrm{sccm})$, and current densities $\left(0\right.$ to $\left.0.38 \mathrm{~A} / \mathrm{cm}^{2}\right)$. Steam consumption rates associated with electrolysis were measured directly using inlet and outlet dewpoint instrumentation. Cell operating potentials and cell current were varied using a programmable power supply. Hydrogen production rates up to 100 Normal liters per hour were demonstrated. Values of area-specific resistance and stack internal temperatures are presented as a function of current density. Stack performance is shown to be dependent on inlet steam flow rate.

\section{ACKNOWLEDGMENTS}

This work was supported by the US Department of Energy, Office of Nuclear Energy, Nuclear Hydrogen Initiative Program.

\section{REFERENCES}

1. National Academy of Sciences, National Research Council, The Hydrogen Economy: Opportunities, Costs, Barriers, and $R \& D$ Needs, February, 2004.

2. Yildiz, B., and Kazimi, M. S., "Nuclear Energy Options for Hydrogen and Hydrogen-Based Liquid Fuels Production," MIT-NES-TR-001, September 2003.

3. International Atomic Energy Agency (IAEA), May 1999, Hydrogen as an energy carrier and its production by nuclear power, IAEA-TECDOC-1085.

4. O'Brien, J. E., Stoots, C. M., Herring, J. S., and Lessing, P. A., "Characterization of Solid-Oxide Electrolysis Cells for Hydrogen Production via High-Temperature Steam Electrolysis," Proceedings, $2^{\text {nd }}$ International Conference on Fuel Cell Science, Engineering, and Technology, June 1416, 2004, Rochester, NY, paper\# 2474, pp., $219-228$.

5. Herring, J. S., O’Brien, J. E., Stoots, C. M., Lessing, P. A., Anderson, R. P., Hartvigsen, J. J., and Elangovan, S., "Hydrogen Production from Nuclear Energy via HighTemperature Electrolysis," presented at the 2004 International Conference on Advances in Nuclear Power Plants (ICAPP ‘04), June 13-17, 2004, Pittsburgh, PA. 
6. Herring, J. S., O'Brien, J. E., Stoots, C. M., Lessing, P. A., Anderson, R. P., Hartvigsen, J. J., and Elangovan, S., "Hydrogen Production through High-Temperature Electrolysis Using Nuclear Power," presented at the AIChE Spring National Meeting, New Orleans, April 25 - 29, 2004.

7. O'Brien, J. E., Stoots, C. M., Herring, J. S., and Lessing, P. A., "Performance Measurements of Solid-Oxide Electrolysis Cells for Hydrogen Production from Nuclear Energy," Proceedings, $12^{\text {th }}$ ICONE Meeting, April 25-29, 2004, Arlington, VA, paper \# ICONE12-49479. 